\title{
Transtorno de déficit de atenção/hiperatividade à luz de uma abordagem crítica: um estudo de caso
}

A critical approach to attention-deficit hyperactivity disorder: a case study

Trastorno por déficit de atención/hiperactividad a la luz de un efoque crítico: un estudio de caso

\section{Isabella da Silva Arantes Pereira* Janaina Cassiano Silva**}

\begin{abstract}
Resumo
Este trabalho refere-se a um estudo de caso envolvendo o atendimento psicológico clínico de uma menina de seis anos, previamente diagnosticada com transtorno de déficit de atenção/hiperatividade (TDAH). Buscamos promover uma discussão do caso, mostrando sua condução e manejo na perspectiva da Psicologia histórico-cultural, a qual entende o TDAH como um fenômeno complexo e multideterminado. Discutimos também questôes como: medicalização, naturalização dos comportamentos indesejáveis do aluno, bem como, a influência do contexto familiar. A partir da análise desse caso, concluímos que a atenção não deve ser concebida como uma capacidade meramente inata e cerebral, mas como fruto da relação dialética entre um organismo biológico e seu meio histórico-cultural. No tocante à escola, percebemos que esta, ao biologizar comportamentos indesejáveis do aluno, tem contribuído sobremaneira para a perpetuação de ideologias do sistema dominante, geradoras de preconceitos, exclusão e ideias reducionistas do ser humano.
\end{abstract}

Palavras-chave: TDAH; Psicologia histórico-cultural; estudo de caso.

\begin{abstract}
This article refers to a case study involving the clinical psychological treatment of a girl six-year-old, previously diagnosed with AttentionDeficit Hyperactivity Disorder (ADHD). It aims at stimulating discussion of the case, showing how it was handled from the perspective
\end{abstract}

\footnotetext{
Texto recebido em janeiro de 2011 e aprovado para publicação em maio de 2011.

Graduada em Psicologia pelo Instituto Luterano de Ensino Superior de Itumbiara- ILES/Ulbra. E-mail: bella_arantes@ hotmail.com.

** Doutoranda em Educação pela Universidade Federal de São Carlos, mestra em Educação Escolar - Unesp/Araraquara e graduada em Psicologia pela Universidade Federal de Uberlândia. E-mail: janacassiano@hotmail.com.
} 
of Cultural-Historical Psychology, which views ADHD as a complex and multifaceted phenomenon. Topics such as medicalization, ascription of undesirable behavior to the student's innate characteristics, and the influence of family context are discussed. Through the analysis of a case was concluded that attention should not be considered as a merely cerebral and innate capacity, but rather as a result of the dialectic relation between a living being and its social-historical environment. As for the school, it is noted that as it ascribes undesirable behaviors to biological aspects of the student, it contributes greatly to the perpetuation of dominant ideologies that generate prejudice, exclusion, and reductionist ideas relating to human beings.

Keywords: ADHD; cultural-historical Psychology; case study.

\section{Resumen}

Este artículo se refiere a un estudio de caso relacionado con el tratamiento psicológico de una niña de seis años, con diagnóstico de Trastorno por Déficit de Atención/ Hiperactividad. Tratamos promover un debate sobre el caso, mostrando su direccionamiento y gestión con la perspectiva de la Psicología Histórico-Cultural, que considera este trastorno como un fenómeno multidimensional y complejo. Se discuten temas como medicalización, naturalización de los comportamientos indeseables de los estudiantes, así como la influencia del contexto familiar. A partir del análisis de este caso, se concluye que la atención no debe ser concebida como una capacidad meramente innata y cerebral, sino como resultado de la relación dialéctica entre el organismo biológico y su entorno histórico-cultural. Con respecto a la escuela, nos damos cuenta de que ésta, al biologizar comportamientos indeseables de los estudiantes, ha contribuido a la perpetuación de ideologías del sistema dominante que generaron prejuicios, exclusión e ideas reduccionistas en los seres humanos.

Palabras clave: TDAH; Psicología histórico-cultural; estudio de caso.

\section{Introdução}

- ste artigo se refere a um estudo de caso envolvendo o atendimento psicológico clínico de uma criança de 6 anos, do sexo feminino, com diagnóstico prévio de transtorno de déficit de atenção/hiperatividade (TDAH). Buscou-se promover uma discussão acerca do caso, mostrando sua condução e manejo, partindo da perspectiva da Psicologia histórico-cultural. 
Dessa forma, o artigo se subdivide em três partes. Na primeira, serão trabalhados os aspectos teóricos referentes ao transtorno de déficit de atenção/ hiperatividade (TDAH), analisados à luz da Psicologia histórico-cultural, bem como problematizações referentes ao diagnóstico e à medicalização desse transtorno. Em um segundo momento, será apresentado o estudo de caso, considerando a descrição, seleção e curso de tratamento. Ao final, buscaremos refletir acerca da complexidade do TDAH, visando à não perpetuação de ideologias do sistema dominante, geradoras de preconceitos, exclusão e ideias reducionistas do ser humano.

\section{O transtorno de déficit de atenção/hiperatividade à luz da Psicologia histórico-cultural}

O transtorno de déficit de atenção/hiperatividade (TDAH) é, na atualidade, um dos diagnósticos psiquiátricos mais frequentes na infância e, conforme o DSM-IV (American Psychiatric Association, 1994), engloba dois tipos de sintomas: desatenção e hiperatividade-impulsividade, podendo haver predomínio de desatenção, predomínio de hiperatividade-impulsividade, ou os dois grupos de sintomas combinados. O panorama histórico mostra que o interesse em tais comportamentos foi despertado no início do século XX, tendo, desde então, surgido várias mudanças na terminologia e controvérsias na concepção desse quadro, o qual nem sempre foi caracterizado como um distúrbio (Brzozowski, 2009; Eidt \& Tuleski, 2007a).

Embora tenha aumentado significativamente o número de investigaçôes acerca dos fatores etiológicos do TDAH nos diversos campos ligados à saúde e à educação, há ainda mais hipóteses e questionamentos do que confirmações. Benczik (2000) levanta como possíveis causas os fatores bioquímicos, neurológicos, neuropsicológicos, ambientais (problemas familiares) e genéticos, atribuindo a este último aspecto um peso importante no desencadeamento do transtorno.

Mesmo com todas as lacunas e controvérsias existentes, muitos estudos e publicaçôes existentes abordam e enfocam o TDAH como um fenômeno que envolve essencialmente fatores individuais e biológicos, desprezando a importância de aspectos sócio, culturais e históricos na constituição e estruturação dos diferentes modos de pensar e agir dos indivíduos. Com base nessa reflexão, Eidt \& Tuleski (2007a) escreveram um artigo pautado na abordagem histórico-cultural, no qual apontam a necessidade e urgência da psicologia buscar a compreensão do homem enquanto ser indissociável da meio social no qual está inserido. Dessa forma, as pesquisas científicas 
envolvendo transtornos mentais e de comportamentos, incluindo o TDAH, devem contemplar também a análise do impacto das variáveis históricas, sociais e culturais na construção da subjetividade, ou seja, nas formas individuais de pensar e se comportar.

Para a Psicologia histórico-cultural, o homem e o meio mantêm uma relação dialética, na qual um determina e é determinado pelo outro, dinamicamente (Eidt \& Tuleski, 2007a). Vigotsky (1999) defende que as funções psicológicas superiores, como a memória e a atenção, desenvolvem-se com base na relação do homem com seu meio sociocultural e por intermédio do uso de signos, sendo a linguagem um dos signos mais importantes para desenvolvimento psicológico.

Para Vigotsky (1998), as funções psicológicas superiores, incluindo a atenção, existem primeiramente como atividade interpsicológica nas relações entre pessoas, para, depois, serem internalizadas pela criança, sendo, portanto, oriundas das relações reais entre os sujeitos. Verifica-se, dessa forma, que a atenção não deve ser concebida como uma capacidade meramente inata e cerebral, mas sim muito mais como fruto da relação dialética entre um organismo biológico e seu meio histórico-cultural.

Nessa perspectiva, a educação escolar tem um papel de extrema importância na aquisição pela criança de funções como a atenção. Apesar disso, verifica-se que o fracasso escolar tem sido justificado pela hiperatividade e ou déficit de atenção, eximindo qualquer responsabilidade do contexto escolar e social nos quais a criança está inserida (Eidt \& Tuleski, 2007a).

Conforme Collares \& Moysés (1996), a Medicina, ao longo da história, tem assumido a função de normatizar a vida dos indivíduos e dos grupos sociais, promovendo a exclusão dos indivíduos que adotam condutas que representam ameaça à manutenção do status quo. Verifica-se, então, que o que era tido como características de um indivíduo tornou-se um problema médico, sendo este um fenômeno expressivo nos dias de hoje que recebeu o nome de "medicalização" (Eidt \& Tuleski, 2007a). Crianças que transgridem certas normas sociais, como não ficar quieta por um tempo prolongado, muitas vezes, recebem o diagnóstico de TDAH. Partindo dessa reflexão, tal diagnóstico, assim como o tratamento, podem, portanto, ser tratados como um tipo de controle social (Brzozowski, 2009).

A fim de evitar uma análise crítica dos conflitos e contradições sociais, econômicos e políticos, a sociedade contemporânea busca reprimi-los, ao associá-los às ideias de desordem, perigo e crise (Eidt \& Tuleski, 2007a). 
Nesse contexto de contenção e exclusão, ocorre uma ampla difusão do uso e prescrição de medicamentos, os quais se colocam como um instrumento simples e concreto, sendo, por isso, bem aceitos pela sociedade, uma vez que promovem uma solução rápida para o problema.

\section{Transtorno de déficit de atenção/hiperatividade $\mathrm{X}$ diagnóstico}

Embora muitas pesquisas tratem o TDAH como transtorno genético e neurológico, seu diagnóstico continua sendo fundamentalmente clínico. Isso significa que o especialista dispõe apenas de conhecimentos técnicos, teóricos, critérios de diagnósticos do DSM-IV (American Psychiatric Association, 1994) e de dados fornecidos por pessoas ligadas a criança para estabelecer um diagnóstico e tratamento adequado (Brzozowski, 2009). Por conseguinte, segundo Machado e Cezar (2008), é de extrema importância um exame clínico detalhado que abarque informações oriundas de professores, pais e indivíduos que compõem a rede de apoio da criança; uma investigação do funcionamento intelectual, social, emocional e acadêmico, exame físico, assim como a aplicação de instrumentos de avaliação psicológica e ou neurológica.

O diagnóstico cauteloso baseado em uma investigação ampla tem uma importância ainda maior, considerando-se que os limites que distinguem um transtorno mental de outro são difíceis de serem estabelecidos. Além disso, o fato de o diagnóstico ser essencialmente clínico o torna ainda mais delicado, uma vez que se baseia principalmente em interpretações e conclusões que sofrem interferência da subjetividade do profissional que o faz.

Geralmente as primeiras queixas sobre indisciplina, impulsividade e agitação da criança, associados ou não a problemas de aprendizagem, advêm da escola, pois é nesse ambiente que tais comportamentos são enfatizados. Nesse sentido, o relato por parte do professor tem uma contribuição relevante para um diagnóstico apropriado. Porém pesquisas apontam que muitos educadores, assim como pais e a sociedade em geral não têm um conhecimento correto da sintomatologia do transtorno, apontando para a necessidade de capacitar profissionais e difundir informações adequadas sobre o assunto (Coutinho et alii 2009; Gomes et alii, 2007).

Em um estudo recente feito por Landskron \& Sperb (2008), no qual foi investigada a percepção de professores sobre TDAH, os resultados indicaram que tais profissionais veem esse transtorno como individualizante e patologizante. Tais achados reforçam novamente a necessidade de uma visão ampla dos elementos envolvidos nesse quadro, que não reduza o ser humano a fatores biológicos, mas que o conceba e o compreenda de forma integral, 
em seus múltiplos aspectos, assim como proposto pela Psicologia históricocultural.

\section{O transtorno de déficit de atenção/hiperatividade e a medicalização incontrolada}

O TDAH é tratado atualmente com o uso de fármacos psicoestimulantes, como o metilfenidato, cujo um dos nomes comerciais é Ritalina ${ }^{\circledR}$ (Brzozowski, 2009). Em cerca de 70 a $80 \%$ dos casos, esse medicamento pode promover a melhora na concentração e redução do comportamento antissocial, porém parece não ter efeitos benéficos sobre o desempenho acadêmico em longo prazo. Ademais, as consequências da terapêutica medicamentosa com crianças são incertas (AAP Comitee on Children with Disabilities and Comitee on Drugs, 1996 citado por Papalia \& Olds, 2000; McDaniel, 1986 citado por Papalia \& Olds, 2000; "Ritalin Improves Behaviour", 1995 citado por Papalia \& Olds, 2000; Zametkin, 1995 citado por Papalia \& Olds, 2000). Assim, favorecendo os interesses de uma forte indústria farmacêutica que vem crescendo e se tornando uma grande fonte lucrativa, o consumo de medicamentos psicotrópicos, como o metilfenidato, tem atingido proporções alarmantes. Itaborahy (2009), em sua dissertação de mestrado, na qual faz uma análise sobre as publicações brasileiras sobre o uso da Ritalina ${ }^{\circledR}$, aponta que esse medicamento é o psicoestimulante mais consumido no mundo, sendo que, apenas no Brasil, no ano de 2007, foram vendidas cerca de 1 150000 de caixas de metilfenidato. Ao discutir o tema, a autora denuncia os valores morais, sociais, políticos e econômicos por trás das produçôes científicas sobre medicamentos, destacando que o aumento das vendas desse psicofármaco está associado ao TDAH, já que anteriormente não havia um diagnóstico específico para seu uso. Verifica-se então que o discurso médico, instrumentalizado pela produção acadêmica, divulga princípios, valores e crenças, os quais não devem ser tratados como verdade absoluta e natural, mas sim com base no contexto histórico-cultural no qual estão inseridos. Portanto, partindo dessa perspectiva de que o conhecimento científico é uma produção social, a dicotomia homem-ciência não deve existir, uma vez que o ser humano constrói o conhecimento científico, o qual, por sua vez, influencia as formas de pensar e agir do primeiro, caracterizando um movimento dialético e simultâneo, no qual as partes se encontram indissociáveis e integradas.

Migueloti (2008) promove uma análise sobre a influência da indústria farmacêutica na produção de pesquisas na área médica, objetivando testar novos medicamentos e procedimentos. Segundo a autora, o patrocínio dos 
produtores de medicamentos na elaboração de estudos científicos trata-se de um apoio estratégico, já que visa, em primeiro plano, à obtenção de lucros e não o comprometimento com a saúde e segurança dos consumidores. Assim, o saber médico, legitimado cientificamente por meio de pesquisas, contribui significativamente para a propagação e manutenção de ideologias, bem como para alimentar os interesses financeiros de um sistema de produção baseado no lucro.

Segundo Itaborahy (2009), existem controvérsias sobre os efeitos do uso do metilfenidato. Há autores que defendem seu uso, afirmando que este não causa dependência, sendo prejudicial ao indivíduo apenas quando administrado de forma abusiva. Acrescenta-se ainda que o tratamento precoce traz benefícios, uma vez que reduz as chances de a criança se tornar um dependente químico no futuro. Já os autores que se opõem ao uso da Ritalina ${ }^{\circledR}$ afirmam que, além da dependência física, a substância tem potencial também para gerar dependência psicológica e emocional, devido à associação do emprego desse medicamento com o bom desempenho escolar.

Breggin (2002 citado por Brzozowski, 2009) aponta, como um dos efeitos desse medicamento, a redução do comportamento espontâneo bem como a submissão forçada, tornando a criança menos comunicativa e menos suscetível à relação com os colegas.

Dado o exposto, essa breve introdução tem por objetivo promover uma reflexão sobre o TDAH como um fenômeno complexo e multideterminado que, dessa forma, não pode ser tratado com base em um único viés. Nesse sentido, o psicólogo, cuja intervenção pauta-se na abordagem dialética, tem muito a contribuir, uma vez que defende uma análise critica desse transtorno, baseando-se na compreensão do indivíduo como espelho de seu tempo histórico e de suas relações sociais.

\section{Apresentação do caso}

\section{Descrição da paciente ${ }^{1}$}

Ana $^{2}$, sexo feminino, 6 anos, branca, estudante do primeiro ano do ensino fundamental de uma escola pública, buscou atendimento psicológico por iniciativa dos pais, os quais apresentaram as seguintes queixas: agressividade, falta de limites, agitação e TDAH diagnosticado previamente por um médico

\footnotetext{
Cabe salientar que todas as informações contidas na descrição da paciente foram coletadas nas sessões de acolhimento e no início da intervenção psicoterápica a partir de encontros com os pais, a criança e a professora. O atendimento descrito neste artigo teve início em agosto de 2009 e término em maio de 2010.

Nome fictício utilizado para preservar o sigilo acerca da identidade da paciente.
} 
neurologista. Segundo os pais, a procura por apoio profissional, tanto médico quanto psicológico, foi motivada por constantes reclamações da escola (professores, coordenadora e diretora) sobre o comportamento da filha. Antes de ser encaminhada para o atendimento, a paciente e os pais passaram por um processo de acolhimento com duração de três encontros, que teve como objetivo principal acolher a demanda e investigar aspectos relacionados à história de vida da criança e seu desenvolvimento.

A criança vive com os pais, os quais possuem, em conjunto, uma renda mensal de cerca de meio salário mínimo. A mãe de Ana, 46 anos, tem segundo grau incompleto, trabalha como diarista duas vezes por semana. $\mathrm{O}$ pai, 57 anos, tem ensino fundamental incompleto. Atualmente se encontra desempregado. Segundo relato dos pais, Ana passa a maior parte do tempo em casa com o pai enquanto ela não está na escola e tem dificuldades de se relacionar com crianças de sua idade, preferindo ter contato com as de idade inferior à dela. Tem dois irmãos adultos, frutos de casamentos anteriores de seus pais, porém tem pouco contato com eles. Nas entrevistas iniciais, foi possível verificar, no ambiente familiar, a ocorrência frequente de conflitos conjugais, incluindo agressões físicas por parte do pai contra a mãe, muitas vezes presenciadas pela filha. $\mathrm{O}$ pai de Ana afirma não concordar com a forma com qual a esposa lida com a filha, culpando-a pelos comportamentos inadequados de Ana relacionados à falta de limites e indisciplina. A mãe, por sua vez, coloca-se como submissa ao marido, admitindo ter dificuldades em atribuir autonomia e responsabilidade à filha, obter respeito dela e fazer com que ela acate ordens, necessitando apelar algumas vezes para agressóes físicas e gritos.

Quanto ao período gestacional, a mãe de Ana relata que sua gravidez não foi planejada, contudo bem recebida pelo casal, acrescentando que amamentou por apenas alguns meses até seu leite secar. Segundo a genitora, sua filha é uma criança inquieta, impõe seus desejos, é indisciplinada, porém muito esperta, não apresentando dificuldades de aprendizagem, em sua percepção.

Apesar da baixa renda financeira, percebe-se que a mãe de Ana valoriza muito a aparência e a higiene da filha, a qual sempre compareceu às sessões bem vestida e limpa. O casal mora em uma casa alugada, em um bairro afastado da região central da cidade. Não possui veículo e utiliza os serviços públicos de saúde. A religião mencionada é o espiritismo. A criança demonstra uma maior proximidade afetiva da mãe, expressando carinho por meio de abraços e verbalizaçôes, os quais são retribuídos pela genitora. 
Ana toma Ritalina ${ }^{\circledR}$ duas vezes ao dia, receitada por um médico neurologista indicado pela escola. O psicofármaco foi prescrito logo na primeira visita ao médico, tendo o diagnóstico se pautado essencialmente no diálogo com os pais. Nestes últimos, pôde-se perceber a presença de crenças relacionadas ao valor terapêutico do medicamento e supremacia do saber médico, bem como conhecimento precário e limitado acerca do transtorno diagnosticado na filha. Em termos culturais, foi verificada dominância masculina na hierarquia familiar, assim como crenças parentais na punição física e verbal (gritos) como forma de educar e controlar os comportamentos da filha.

Quanto à vida escolar, Ana é aluna do primeiro ano do ensino fundamental de uma escola municipal; frequenta aulas no período da manhã; é pontual e assídua, faltando apenas em circunstâncias especiais. Os pais de Ana são frequentemente chamados à escola devido a queixas relacionadas ao comportamento da filha, porém apenas a mãe comparece. A professora de Ana a relata como uma criança agitada, indisciplinada, ocasionalmente agressiva com os colegas e com dificuldades no cumprimento de tarefas, em acatar ordens e respeitar regras. Por outro lado, afirma que, apesar de tais características, é uma criança muito dócil, sincera, meiga e inteligente, equiparando seu comportamento a de um adulto em termos de linguagem, raciocínio e comunicação. Segundo a docente, Ana apresenta um desempenho escolar inferior à maioria dos colegas, pois não consegue se concentrar nas atividades e demonstra baixa perseverança em aprender. Não consegue ler e tem dificuldades em formar sílabas, escrevendo palavras a partir da soletração e ou desenho das letras. Entretanto, nos últimos dois meses, foi relatada pela professora uma significativa mudança no comportamento da criança, a qual tem demonstrado mais obediência, respeito aos colegas e interesse em participar das atividades escolares. Sua postura em sala é de liderança, expressando agressividade quando não tem a atenção dos colegas ou em uma situação de injustiça.

\section{Seleção e curso do tratamento}

Por defender uma visão integral de homem, o atendimento na vertente histórico-cultural busca contemplar todos os contextos nos quais a criança está inserida, incluindo a vida escolar e familiar. A compreensão desses múltiplos aspectos por parte do psicólogo e da forma como estes interagem na constituição da subjetividade da criança é imprescindível em uma intervenção orientada pela vertente dialética. Assim, foi necessária uma adaptação do atendimento pautado nessa abordagem para o ambiente 
clínico, já que todos os encontros ocorreram nesse espaço, exceto com a professora. Os atendimentos fizeram parte de um estágio profissionalizante em Psicologia Clínica, realizado na clínica-escola de uma instituição de ensino superior, localizada no Sul de Goiás.

No total, foram realizadas 25 sessões ao longo de nove meses: 19 encontros com a criança (semanais), dois com os pais, um com o pai e com a mãe separadamente e dois com as professoras (atual e anterior). Cada sessão teve duração de aproximadamente 50 minutos.

Os primeiros encontros com Ana tiveram caráter essencial de avaliação, objetivando verificar seu funcionamento integral, construir o vínculo terapeuta-paciente e fornecer esclarecimentos sobre o papel do psicólogo e a função da psicoterapia. Nessa etapa, foram desenvolvidas diferentes atividades, como leitura do livro "O primeiro livro da criança sobre psicoterapia” (Nemiroff \& Annunziata, 1995), o qual retrata, pelo ponto de vista da criança, questionamentos e preocupaçóes ligados ao atendimento psicológico; aplicação da escala de maturidade mental Columbia (EMMC) (Alves \& Duarte, 1993), a qual avalia a aptidão geral de raciocínio de crianças entre 3 anos e 6 meses e 9 anos e 11 meses de idade; atividades lúdicas envolvendo desenhos e dramatizaçôes com fantoches e brinquedos, confecção da caixa de "problemas", na qual ela poderia depositar ou retirar problemas (escritos em uma tira de papel) a cada sessão, e da caixa de brinquedos.

Nessa fase de avaliação foram verificados os seguintes aspectos: presença de conflitos no ambiente escolar envolvendo agressões físicas e verbais por parte da criança em relação aos colegas; sentimentos de hostilidade e medo com respeito ao pai, associando sua figura a punições físicas e verbais; consciência do nome do medicamento que ingere e do diagnóstico de TDAH; preocupação excessiva em manter roupas e calçados limpos devido a receio de castigo parental; proximidade afetiva da figura materna, atribuindo a esta a função de proteção. Durante as atividades, Ana demonstrou autonomia na execução das tarefas (apontar lápis, abrir caixa, guardar brinquedos), agitação, porém não em excesso; cooperação (ao final das sessões, ajudou a organizar os brinquedos quando foi solicitada); ótima capacidade de comunicação, interação e linguagem adequada à sua faixa etária (pronúncia correta de palavras, compreensão das perguntas feitas). No tocante ao teste, o resultado (percentil 96) indicou que a criança teve um escore igual ou melhor do que $96 \%$ das crianças de seu grupo etário, o que a coloca muito acima da média em termos de capacidade de raciocínio geral. 
Com base nos dados coletados nesses primeiros encontros, foi levantada a hipótese preliminar de que a falta de limites e a agressividade manifestada por Ana na escola estaria sendo aprendida principalmente no ambiente familiar, a partir de modelos transmitidos por seus pais. As observações realizadas nesse período também trouxeram questionamentos sobre o diagnóstico de TDAH feito pelo médico neurologista, já que, durante os encontros, a criança demonstrou concentração na realização das atividades e baixa inquietação. Cabe ressaltar que, embora a criança estivesse sob tratamento com Ritalina ${ }^{\circledR}$, tal fato não interferiu significativamente nas observações realizadas durante a fase de avaliação, uma vez que a droga não apresenta efeito cumulativo. O medicamento era ingerido no período matutino, e as sessões, realizadas no final da tarde, de modo que, durante $o$ atendimento, a paciente se encontrava sob pouco ou nenhum efeito do psicoestimulante.

Diante dessas percepções, os encontros posteriores com Ana tiveram como foco principal a queixa relativa à agressividade na escola e à falta de limites. Nestes, buscou-se estimular na criança a adoção de uma postura empática e a conscientização acerca de seus afetos e do controle que pode exercer sobre suas ações e atitudes. Foram trabalhados aspectos como: expressão de sentimentos (medo, raiva, alegria); a relação com os pais, professor e colegas de escola; respeito a regras; baixa tolerância à frustração; importância e o papel da instituição escolar; comportamento de empatia; e a busca de estratégias comportamentais não agressivas na resolução de conflitos. Entre as atividades desenvolvidas, destacam-se: dramatizações com fantoches e brinquedos, usando a técnica da inversão de papéis; histórias; desenhos; jogos interativos; colagem; recorte; e vídeos de animação.

Como estratégia para trabalhar a queixa de indisciplina, foi utilizado um "quadro de rotina" contendo atividades diárias da criança, o qual deveria ser preenchido pelos pais semanalmente e levado às sessões. A cada tarefa cumprida com sucesso, a criança receberia uma "carinha feliz" e, caso contrário, uma "carinha triste". Ao final, deveria receber uma recompensa, preferencialmente não material.

O "quadro de rotina" é uma forma de mostrar aos pais a importância da disciplina na vida da criança. Porém cabe ressaltar, de acordo com Makarenko (1981, p. 38), que "A disciplina não se cria com algumas medidas disciplinárias, mas com todo o sistema educativo, com a organização de toda a vida”. Ou seja, esta seria a somatória de todas as influências que estão relacionadas à criança. "A disciplina não é uma 
causa, um método, um procedimento de educação, mas o seu resultado" (Makarenko, 1981, p. 38). Sendo assim, o "quadro de rotinas" representa uma ferramenta de suporte na educação da criança.

No período inicial da intervenção psicoterapêutica, Ana demonstrou dificuldade em se concentrar na realização de tarefas com tempo prolongado (maior que 30 minutos), indisciplina e baixa tolerância à frustração. Durante a realização de jogos interativos, apresentou postura de liderança e resistência na aceitação das regras estabelecidas, mesmo quando estas eram formuladas e pré-acordadas por ela. Diante da ameaça de uma possível derrota, Ana insistia em mudar as regras do jogo, de modo a favorecer sua vitória, demonstrando sentimento de hostilidade em relação ao terapeuta quando sua vontade não era atendida e suas expectativas frustradas.

Apesar de Ana ter inicialmente se oposto a aceitar as regras instituídas, esse comportamento não se manteve sólido e constante. O diálogo orientador e esclarecedor, as interações com o terapeuta e a postura ativa e acolhedora deste se colocaram como elementos essenciais para essa mudança de conduta por parte da criança.

Com relação à importância dos jogos na infância, Elkonin (1969) destaca que estes propiciam a criança conhecer as atividades dos adultos, seus papéis e as relaçôes sociais que estabelecem entre si, sendo, portanto, um instrumento de formação da esfera moral. Segundo o autor, "no jogo se formam tipos mais elevados da percepção, do processo verbal, da imaginação e se efetua o passo do pensamento objetivo a outras formas mais abstratas" (Elkonin, 1969, p. 514-515).

Por Ana ter demonstrado resistência em respeitar as regras da sessão no tocante aos horários estabelecidos, foi dado à paciente um relógio, o qual serviria como um referencial de tempo acerca da duração das atividades e do término da sessão. Vale destacar que tal procedimento foi bem aceito pela criança, atingindo, dessa maneira, seu propósito.

Outra questão importante observada diz respeito à excessiva preocupação da criança em se manter limpa durante o manuseio de frascos de tinta e pincéis, refletindo o receio em relação à punição parental. No tocante a esse aspecto, foi feita uma orientação à mãe, na presença da criança, com relação ao uso desse material nas sessões, colocando o fato de se sujar como algo esperado e comum. Tal iniciativa, associada à ênfase acerca do sigilo durante os encontros, proporcionaram o fortalecimento do vínculo com o terapeuta e a diminuição da tensão da paciente ao se expressar pela produção artística. 
Entre as atividades utilizadas para trabalhar a queixa de agressividade, a dramatização com fantoches usando a técnica da inversão de papéis foi um instrumento muito rico, por despertar empatia na criança e lhe mostrar os aspectos negativos que a adoção de um comportamento agressivo gera.

Ao longo dos encontros, Ana passou a demonstrar cooperação, gratidão quando lhe foi fornecida ajuda, afetividade, entusiasmo, autonomia na busca de soluções para problemas, empatia, concentração na realização de tarefas mais prolongadas e concordância com as regras propostas. Durante as sessões e na entrevista com a professora, pôde-se perceber ainda uma mudança positiva na imagem atribuída pela criança à escola, nas tarefas escolares e no comportamento em termos de disciplina e respeito a regras nesse contexto.

Diante do progresso significativo em relação às queixas iniciais (agressividade, mau humor, falta de limites) e da realização de um novo diagnóstico por um segundo médico neurologista, descartando a hipótese da presença de TDAH apontada no laudo anterior, deu-se início ao encerramento do processo terapêutico.

Durante as sessões finais, foi fornecido a Ana um feedback sobre a boa evolução do seu caso e realizada algumas atividades para revisar os tópicos que haviam sido trabalhados durante a psicoterapia (agressividade, respeito a regras, visão da escola, empatia, etc.). Apesar de ter manifestado frustração e descontentamento com o término do processo psicoterápico, falando várias vezes, durante esse período, que não queria ir embora, Ana demonstrou estar ciente de sua melhora e da resolução de suas queixas iniciais.

Os três primeiros encontros feitos com os pais, em conjunto e individualmente, assim como a primeira visita à professora (anterior) tiveram caráter de investigação. Os principais elementos verificados nesses encontros foram mencionados acima na descrição da vida familiar e escolar de Ana respectivamente.

Ao final do processo psicoterápico, foi realizado um encontro com a nova professora da criança e outro com os pais. $\mathrm{O}$ encontro com a primeira teve o objetivo de avaliar aspectos da vida escolar da criança (relação com professora, com os colegas, desempenho escolar, queixas, mudanças, etc.). Nele, a docente relatou melhoras significativas em relação à falta de limites e respeito a regras por parte de Ana, porém se verifica que a professora ainda encontra obstáculos e dificuldades em lidar com comportamentos de inquietação e agitação da criança, mesmo que estes não sejam frequentes. Além disso, foi percebida uma lacuna na comunicação entre escola e pais. Tais observações levantaram a necessidade da realização de intervenções na instituição escolar 
e que possam abarcar todos os autores que dela fazem parte (pais, professores, alunos, funcionários e comunidade).

O último encontro com os pais teve como finalidade fornecê-los um feedback sobre o processo terapêutico, orientá-los sobre a manutenção dos comportamentos positivos da filha e encaminhá-los para um grupo de orientação de pais. Nessa ocasião, eles relataram que a criança teve melhoras significativas de comportamento em casa e no desempenho escolar.

\section{Consideraçóes finais}

Pela análise desse caso, pôde-se concluir que as manifestações comportamentais de Ana, incluindo agressividade, indisciplina, falta de limites, bem como suas crenças de incapacidade de aprender, refletem diretamente as relações sociais estabelecidas nos contextos nos quais se encontra inserida. Quanto ao diagnóstico de TDAH, não foram observadas na criança, durante as sessões, condutas que o confirmassem ou levantassem a hipótese de sua presença. Ao final do processo psicoterápico, um segundo laudo, emitido por outro médico neurologista, confirmou nossa hipótese, descartando a presença do transtorno.

Tais resultados demonstram o despreparo e falta de capacitação do médico que atendeu inicialmente a criança em realizar um diagnóstico adequado, que resulte de uma investigação ampla e cautelosa de todos os aspectos relacionados ao indivíduo. Demonstram ainda, por parte da escola, baixa tolerância e consequente naturalização daqueles comportamentos tidos como inadequados, o que contribui para a impressão de rótulos de exclusão ao transferir para o campo médico a responsabilidade pelo progresso educacional dos alunos.

No âmbito familiar, pôde-se verificar que a genitora superprotege a criança, fornecendo-lhe pouco estímulo para a realização de tarefas de forma autônoma, o que se coloca como mais um obstáculo ao seu aprendizado de forma geral. Durante as sessões, essa postura materna se refletia na desmotivação de Ana em realizar atividades que envolvessem maior esforço intelectual, desencadeada por crenças na sua incapacidade de aprender. Meira (2007), pautando-se nos princípios da Psicologia histórico-cultural, coloca que a aquisição de novas aptidóes e o desenvolvimento de funçôes psíquicas, como atenção e memória, resultam do processo de apropriação dos conhecimentos construídos ao longo da história, o qual apenas se torna possível por meio da interação 
social e por intermédio do uso de signos, como a linguagem. Nesse sentido, tanto os pais quanto a escola devem assumir um papel ativo, que contribua para esse processo de humanização.

As interações da criança com seus diversos contextos, especialmente com o escolar, devem promover a aquisição da cultura humana acumulada ao longo das geraçôes, o desenvolvimento de uma postura crítica e reflexiva que rompam com preconceitos, com a alienação e com ideias reducionistas acerca do ser humano.

Ao longo dos encontros com a criança, ficou cada vez mais evidente que sua agressividade manifestada na escola estava sendo aprendida no ambiente familiar, especialmente por meio da figura paterna. $\mathrm{O}$ apelo para a agressão física e verbal como estratégia de coerção, punição e resolução de conflitos por parte dos pais revelam a ausência de diálogo, de tolerância e de integração entre os membros familiares. Vigotsky (1998) aponta que o sujeito apropria-se de novas atividades e formas de se relacionar com o mundo, por meio das quais desenvolve modelos culturais de comportamento. Dessa forma, a aquisição de funções psíquicas superiores está totalmente à mercê das condições objetivas de vida e aprendizagens (Martins, 2007), de modo que, na concepção materialista dialética, o homem não aprende e se desenvolve por si só, mas sim pela qualidade das relações que estabelece com seu meio social.

No tocante à escola, percebe-se que esta, ao biologizar comportamentos indesejáveis do aluno, tem contribuído sobremaneira para a perpetuação de ideologias do sistema dominante geradoras de preconceitos, exclusão e ideias reducionistas do ser humano. Segundo Saviani (1997 citado por Facci, 2007), para que o professor promova nos alunos a apropriação do saber construído pela humanidade, precisa dominar: os conhecimentos específicos da disciplina; conhecimento didático-curricular, ou seja, saber como transmitir adequadamente os conhecimentos específicos; "saber pedagógico", produzido pelas ciências da educação; compreensão das condições sócio-históricas que influenciam a tarefa de educar; e "saber atitudinal", domínio de comportamentos adequados ao trabalho educativo. Verifica-se, com base nisso, a necessidade de uma capacitação dos professores que envolva a transmissão de conhecimento científico que propicie uma visão crítica sobre a prática, o aluno e o processo de ensino-aprendizagem.

Embora de forma gradual, as intervenções realizadas trouxeram resultados positivos: diminuição das manifestações agressivas e 
indisciplina na escola; maior interesse na participação das atividades propostas; melhor aceitação e respeito às regras estabelecidas; menor receio quanto à punição física materna, embora o medo de castigo físico paterno tenha permanecido. Tais mudanças foram facilitadas por aspectos como a qualidade do vínculo criado com a paciente, o reforço quanto ao sigilo das informaçôes e a postura empática do terapeuta.

Ademais, a participação e engajamento de ambos os pais no processo terapêutico (presença nos encontros, cooperação na realização das tarefas propostas para casa, interesse e aceitação em participar da orientação de pais) foi essencial para que este fosse realizado de modo satisfatório.

A análise do caso apresentado e seu desfecho trazem à tona a relevância dos estudos sobre TDAH pautados em abordagens críticas, que apontem para os múltiplos aspectos envolvidos na produção e manutenção desse transtorno, rompendo, dessa forma, com visões estigmatizantes e reducionistas. Reflexões como esta têm extrema relevância, uma vez que, denunciando mecanismos de controle e padrões de conduta reforçadores de ideais dominantes e preconceituosos, buscam minimizar a medicalização desenfreada, presente no Brasil, nos dias atuais.

\section{Referências}

Alves, I. C. B. \& Duarte, J. L. M. (1993). Escala de maturidade mental Colúmbia: padronização brasileira. São Paulo: Casa do Psicólogo.

American Psychiatric Association. (1994). DSM-IV: Diagnostic and Statistical Manual of Mental Disorders. Washington D.C.: American Psychiatric Association.

Benczik, E. B. P. (2000). Transtorno de déficit de atenção/hiperatividade: atualização diagnóstica e terapêutica. São Paulo: Casa do Psicólogo.

Brzozowski, F. S. (2009). Transtorno de déficit de atenção com hiperatividade: medicalização, classificação e controle dos desvios. Dissertação de mestrado, Programa de Pós-graduação em Saúde Pública, Universidade Federal de Santa Catarina, Florianópolis.

Collares, C. A. L. \& Moysés, M. A. A. (1996). Preconceitos no cotidiano escolar: ensino e medicalização. São Paulo: Cortez. 
Coutinho, G. et alii. (2009). Concordância entre relato de pais e professores para sintomas de TDAH: resultados de uma amostra clínica brasileira. Revista de Psiquiatria Clínica, 36 (3), 97-100.

Eidt, N. M. \& Tuleski, S. C. (2007a). Discutindo a medicalização brutal em uma sociedade hiperativa. In: Meira, M. E. W. \& Facci, M. G. D. (Org.). Psicologia Histórico-Cultural: contribuiçôes para o encontro entre a subjetividade e a educação. (pp. 221-248). São Paulo: Casa do Psicólogo.

Eidt, N. M. \& Tuleski, S. C. (2007b). Repensando os distúrbios de aprendizagem a partir da Psicologia Histórico-Cultural. Psicologia em Estudo, $12(3), 531-540$.

Elkonin, D. B. (1969). Desarrollo psíquico de los niños. In: Smirnov, A. A. (Org.). Psicologia. (pp. 493-560). México: Grijalbo.

Facci, M. G. D. (2007). "Professora, é verdade que ler e escrever é uma coisa fácil?”- Reflexões em torno do processo ensino-aprendizagem na perspectiva vigotskiniana. In: Meira, M. E. W. \& Facci, M. G. D. (Org.). Psicologia Histórico-Cultural: contribuiçôes para o encontro entre a subjetividade e a educação. (pp. 135-155). São Paulo: Casa do Psicólogo.

Gomes, M. et alii (2007). Conhecimento sobre o transtorno do déficit de atenção/hiperatividade no Brasil. Jornal Brasileiro de Psiquiatria, 56 (2) 94-101.

Itaborahy, C. (2009). A Ritalina no Brasil: uma década de produção, divulgação e consumo. Dissertação de mestrado, Programa de Pós-graduação em Saúde Coletiva, Universidade do Estado do Rio de Janeiro, Rio de Janeiro.

Landskron, L. M. F. \& Sperb, T. M. (2008). Narrativas de professoras sobre o TDAH: um estudo de caso coletivo. Revista Semestral da Associação Brasileira de Psicologia Escolar e Educacional, 12 (1), 153-167.

Machado, L. F. J. \& Cezar, M. J. C. (2008). Transtorno de déficit de atenção e hiperatividade (TDAH) em crianças- reflexões iniciais. Revista Psicopedagogia On-line. Recuperado de http://www.psicopedagogia.com.br/artigos/artigo. asp?entrID=1030 em 14 de novembro, 2009.

Makarenko, A. S. (1981). Conferências sobre educação infantil. (Maria Aparecida Abelaira Vizotto, Trad.). São Paulo: Moraes.

Martins, L. M. (2007). Algumas reflexões sobre o desenvolvimento omnilateral dos educandos. In: Meira, M. E. W. \& Facci, M. G. D. (Org.). 
Psicologia Histórico-Cultural: contribuiçôes para o encontro entre a subjetividade e a educação. (pp. 117-134). São Paulo: Casa do Psicólogo.

Meira, M. E. M. (2007). Psicologia Histórico-Cultural: fundamentos, pressupostos e articulações com a psicologia da educação. In: Meira, M. E. W. \& Facci, M. G. D. (Org.). Psicologia Histórico-Cultural: contribuiçôes para o encontro entre a subjetividade e a educação. (pp. 27-62). São Paulo: Casa do Psicólogo.

Migueloti, V. (2008). A induistria do conhecimento, o médico e a indústria farmacêutica: uma coprodução de técnicos e técnicas de poder. Dissertação de mestrado, Programa de Pós-graduação em Saúde Coletiva, Universidade do Estado do Rio de Janeiro, Rio de Janeiro.

Nemiroff, M. A. \& Annunziata, J. (1995). O primeiro livro da criança sobre psicoterapia. Porto Alegre: Artmed.

Papalia, D. E. \& Olds, S. W. (2000). Desenvolvimento humano. Porto Alegre: Artes Médicas Sul.

Vigotsky, L. S. (1999). Teoria e método em Psicologia. São Paulo: Martins Fontes.

Vigotsky, L. S. (1998). A formação social da mente. São Paulo: Martins Fontes. 